\title{
Complex ocular trauma outcomes and system capabilities: lessons from a combat zone and implications for national eye trauma care
}

\author{
Marcus H. Colyer $\mathbb{( I}^{1} \cdot$ Robert A. Mazzoli ${ }^{1}$
}

Received: 4 November 2020 / Revised: 9 November 2020 / Accepted: 11 November 2020 / Published online: 12 February 2021

This is a U.S. government work and not under copyright protection in the U.S.; foreign copyright protection may apply 2021

In this month's issue, Gensheimer, Blanch, and Kerber detail the US-UK experience of ophthalmic support to NATO combat operations in Afghanistan from 2017 to 2019. They describe patterns of eye injuries, procedures, and outcomes, and remark on opportunities for future improvement [1]. The manuscript is unique in that it includes epidemiology and outcomes of care for Host National (HN) casualties, an aspect that is often lost in the well-documented reports of expeditionary force casualties over the last two decades [2-4]. Specifically, the authors cite a $44 \%$ rate of retinal detachment in $\mathrm{HN}$ after open globe repair, and visual outcomes that are equally poor for blast-concussed closed globe injuries and ruptures, results that stand in contrast to coalition outcomes from similar wounds. Given the marked disparities in ocular care and capabilities available to NATO casualties once repatriated vs. those available to $\mathrm{HN}$ casualties, the corresponding disparity in outcomes comes as no surprise. This provides a basis for future study. In addition, beyond the authors own conclusions, the article provides a springboard for deep reflection on the nature, character, and increasing frequency of complex ocular polytrauma and the care systems required for optimal treatment (both expeditionary and at home), the appropriate level of ophthalmic sophistication in combat theaters, the application of military medical rules of engagement, and the critical reliance on international cooperation to augment resources in caring for complex ocular polytrauma in vulnerable $\mathrm{HN}$ populations.

The United States Department of Defense (US DOD) delineates moral and legal responsibilities for care of $\mathrm{HN}$ during combat operations. DOD Instruction 6200.07 unambiguously defines specific obligations when encountering $\mathrm{HN}$ casualties, including requirements to provide direct health

Marcus H. Colyer

marcus.h.colyer.mil@mail.mil

1 Uniformed Services University of the Health Sciences, Bethesda, MD, USA care and "appropriate treatment to the extent practical...[to] professional judgements and standards similar to those applied to the treatment of military services in comparable circumstances, particularly in situations that would otherwise likely result in loss of life, limb, or eyesight" [emphasis added] [5]. Authors operated under this directive. That the US DOD recognizes the critical importance of eyesight as a life-altering injury is telling, and underscores the criticality of having ophthalmologists present in any combat theater; yet that need has recently come under scrutiny by allied Defense agencies $[6,7]$. While the proportion of $\mathrm{HN}$ to coalition force care will understandably shift with the tempo of combat operationscertainly this article reports a much higher proportion than prior studies [8], consistent with the decreasing numbers of deployed allied troops-recognition of the contingency for significant HN care must be recognized and deliberately considered in the planning for deployed care capability since the conclusions will inevitably affect personnel, equipment, training and logistics, and ultimately access to care and outcomes. Analogies and parallel concerns can be easily made to domestic civilian ocular trauma care.

Of particular note, the article highlights the disparity when deployed ophthalmologists were required to perform a variety of definitive surgeries on $\mathrm{HN}$ casualties because more sophisticated care was unavailable locally, rather than damage control ophthalmology performed on evacuatable coalition casualties. They adhere to moral and legal responsibilities to deliver "comparable care" within significant limitations of inadequate equipment, personnel and supplies, and personal abilities (often operating solo and outside of their subspecialty) while facing horrific injuries. Most notably-as the most sophisticated ophthalmic resource available for the HN population - they acted to prevent further visual morbidity despite the invariable pattern of complex ocular polytrauma that typically requires a coordinated team of ocular subspecialists with state-of-the-art equipment to prevent blindness. That level of care is available to repatriated casualties after evacuation but is absent in combat zones. This invites the question of defining appropriate surgical capabilities for theater care in the 
inevitable future war, particularly if evacuation is lacking or significantly delayed even for coalition casualties.

Given limited health care resources, we must search broadly for answers to the problem of optimal trauma care in various settings. As an international community, we must fill new and longstanding vacuums of capability and resources at systems levels to reduce the burden of blindness from military trauma and conflicts. A similar challenge exists for peacetime trauma care nationally. To begin this, we must first recognize and agree that a need exists. This article goes to the heart of that gap. Further, efforts to prevent or reduce the burden of ocular trauma and disease must be considered. Establishing formal local, regional, or national referral networks for ongoing care may be a valuable consideration if needed capabilities are limited in local areas. Creating a system to efficiently manage modern ocular injuries-they're not just complicated, they're complex - which require a coordinated milieu of subspecialists (including rehabilitation services) is not easy, but it is essential $[9,10]$. Such a system, designed to ensure the right patient arrives at the right facility with the right ocular capability for the right treatment at the right time, would benefit both military and civil care. This article captures those global challenges in the setting of warzone Afghanistan, with its limited ophthalmologic assets, challenging geographic constraints, large distances, and multifaceted cultural factors.

The authors further discuss the potential for eye protection ("eyepro") in preventing injury in noncombatant populations. Several military publications have demonstrated its effectiveness in reducing the incidence and severity of combat ocular trauma [11, 12]. In particular, Parker highlights the dramatic disparity in rates of injury between NATO forces (wearing eyepro; low incidence) and embedded Afghan National forces (not wearing eyepro; high incidence, often bilateral) [13]. How to increase availability and compliance for these protective measures is an issue not exclusive to combat ocular trauma but germane to society as a whole.

The authors are to be congratulated on their diligence and compassion in attempting to bring state-of-the-art ocular trauma care to a desperately needful population in exceptionally trying circumstances. That outcomes were perhaps not as satisfying as might be achieved elsewhere is no fault of theirs. Lacking the needed sophisticated system of ocular trauma care, one does his or her best. A lasting impact is also made in identifying the need, and this article goes a long way toward that end.

\section{Disclaimer}

The opinions or assertions contained herein are the private ones of the author/speaker and are not to be construed as official or reflecting the views of the United States Army, Department of Defense, the Uniformed Services University of the Health Sciences or any other agency of the U.S. Government.

\section{Compliance with ethical standards}

Conflict of interest The authors declare that they have no conflict of interest.

Publisher's note Springer Nature remains neutral with regard to jurisdictional claims in published maps and institutional affiliations.

\section{References}

1. Gensheimer WG, Kerber MT, Blanch, RB. The epidemiology and outcomes of combat ocular trauma among local nationals managed at a deployed military hospital in Afghanistan. Eye. 2020. in press.

2. Weichel E, Colyer M, Ludlow S, Bower K, Eiseman A. Combat ocular trauma visual outcomes during operations iraqi and enduring freedom. Ophthalmology. 2008;115:2235-45.

3. Breeze J, Blanch R, Mazzoli R, DuBose J, Bowley D, Powers D. Comparing the management of eye injuries by coalition military surgeons during the Iraq and Afghanistan conflicts. Ophthalmology. 2020;127:458-66.

4. Harvey M, Justin G, Brooks D, Ryan D, Weichel E, Colyer M, 2020. Ocular trauma in operation Iraqi freedom and operation enduring freedom from 2001 to 2011: a Bayesian network analysis. Ophthalmic Epidemiol. 2020:1-10. Epub ahead of print.

5. Office of the Undersecretary of Defense, Personnel and Readiness. Delivery of Direct Health Care to Non-Detainee Host Nation (HN) Civilians (DOD Instruction 6200.07). Washington: Department of Defense; 2017.

6. Breeze J, Blanch R, Mazzoli R, DuBose J, Bowley D, Powers D. Comparing the management of eye injuries by coalition military surgeons during the Iraq and Afghanistan conflicts. Ophthalmology. 2020;127:458-66.

7. Maucione S. House panels wants to slow military cuts to medical staff and facilities. Federal News Network. 2020. https://federa lnewsnetwork.com/defense-main/2020/06/house-panel-wants-toslow-military-cuts-to-medical-staff-and-facilities/.

8. Mader T, Carroll R, Slade C, George R, Ritchey J, Neville S. Ocular war injuries of the Iraqi insurgency, January-September 2004. Ophthalmology. 2006;113:97-104.

9. Gonnering R. Is oculofacial surgery complex ... or merely complicated? Curr Opin Ophthalmol. 2018;29:434-9.

10. Bartley G. Learning from our (My) mistakes. Arch Ophthalmol. 2012;130:240.

11. Weinstein O, Mandel Y, Levy J, Lifshitz T, Yitzhak A, Abu Tailakh M. Ballistic eye protection: why are soldiers reluctant to use them? Mil Med. 2018;184:e211-6.

12. Gondusky J, Reiter M. Protecting military convoys in Iraq: an examination of battle injuries sustained by a mechanized battalion during operation Iraqi freedom II. Mil Med. 2005;170: 546-9.

13. Parker P, Mossadegh S, McCrory C. A comparison of the IEDrelated eye injury rate in ANSF and ISAF forces at the UK R3 Hospital, Camp Bastion, 2013: Table 1. J R Army Med Corps. 2013;160:73-4. 